Bulgarian Academy of Sciences. Space Research and Technology Institute.

Aerospace Research in Bulgaria. 32, 2020, Sofia

DOI: https://doi.org/10.3897/arb.v32.e06

\title{
MATHEMATICAL MODEL AND ALGORITHM OF OPERATION OF SYSTEM FOR RELEASE OF LOAD FROM AIRPLANE
}

\author{
Milen Atanasov \\ Aviation Faculty - "Vasil Levski” National Military University \\ e-mail: maatanasov@nvu.bg
}

Keywords: Aviation Systems, Flight Parameters, Mathematical Model, Aircraft

\begin{abstract}
The development of technology allows the accurate delivery of loads from an aircraft at a precise location using aboard aviation systems. For this purpose, a mathematical model and algorithm for a flight aviation system is proposed, which depending on the flight parameters and the coordinates of the load delivery point, automatically determines the release time.
\end{abstract}

\section{Study area}

The moment of load separation is determined by comparing the angular coordinates $\mu_{1}^{\prime}, \varphi_{1}^{\prime}$ at the point (target-T) of delivery and $\mu_{1 \mathrm{~d}}^{\prime}, \varphi_{1 \mathrm{~d}}^{\prime}$ at the point of landing of the load (Fig. 1), [5]:

1)

$$
f_{\mu}=\mu^{\prime}{ }_{1}-\mu^{\prime}{ }_{1 d}=0, f_{\varphi}=\varphi_{1}^{\prime}-\varphi^{\prime}{ }_{1 d}=0 .
$$

where $\mathrm{Ox}_{\mathrm{D}} \mathrm{yz}$ is a distance-to-target coordinate system;

$\mathrm{Ox}_{1} \mathrm{y}_{1} \mathrm{z}_{1}$ - associated coordinate system with the airplane.

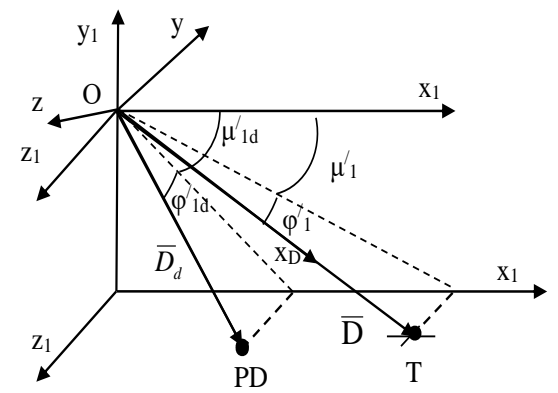

Fig. 1. Determination of angular coordinates in the coordinate system $O x_{1} y_{1} z_{1}$ 
The current position of the target is determined by a tracking system. The position of the Orij coordinate system associated with the tracking device is determined with respect to the horizontally stabilized $O_{t} x y z$ coordinate system (Fig. 2) with the corners $\mu$ and $\varphi$.

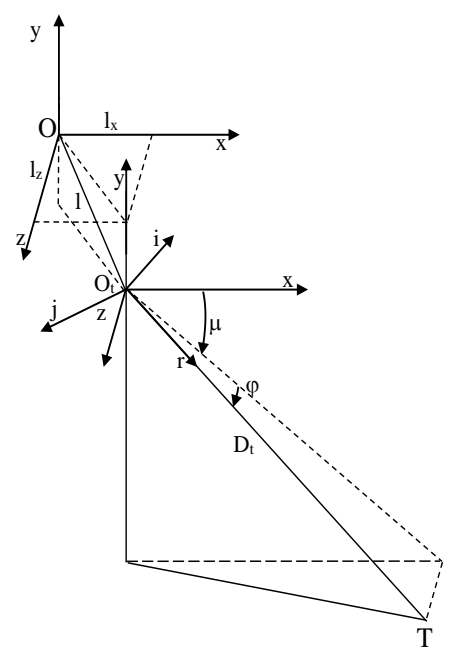

Fig. 2. Determining the position of Orij relative to $O_{t} x y z$

Provided the target is mobile, the vector equation for determining the moment of release of the load from the airplane is determined by the vector scheme (Fig. 3):

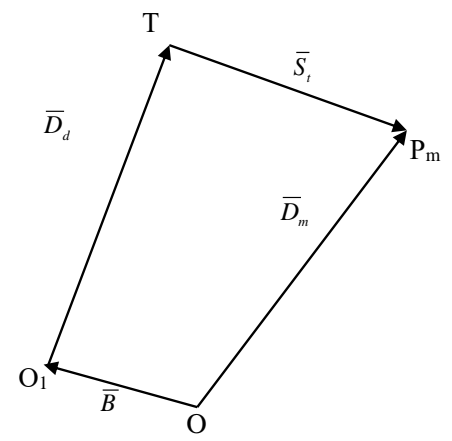

Fig. 3. Vector scheme for determining the moment of load release

2) $\bar{D}_{d}=\bar{D}_{m}-\bar{B}-\bar{S}_{t}$,

where $O O_{1}=\bar{B}$ is the vector of the distance between the loading point and the center of gravity of the airplane; 
$O_{l} T=\bar{D}_{d}$ - the distance vector to the target at the time of release;

$T P_{m}=\bar{S}_{t}$ - the vector of the road traveled by the load flight time;

$O P_{m}=\bar{D}_{m}$ - the vector of the distance to the point of encountering the load with the target.

The vector equation (2) is represented in scaled in the coordinate system $O x_{1} y_{1} z_{1}$.

Vector projections $\left(\bar{S}_{t}\right)_{1}$ in the system $O x_{l} y_{l} z_{l}$, are determined using the formula:

3)

$$
\left(\bar{S}_{t}\right)_{1}=\left[\begin{array}{c}
V_{t x 1} T \\
V_{t y 1} T \\
V_{t z 1} T
\end{array}\right],
$$

where $T$ is time of load flight, $\left(\bar{V}_{t}\right)_{1}$ is the speed of the target in the system $\mathrm{Ox}_{1} \mathrm{y}_{1} \mathrm{z}_{1}$.

The vector equation for determining the speed of the moving target is derived from Fig. 2 and Fig. 3 [5]:

4) $\quad \bar{V}_{t}=\bar{W}+\bar{\omega}_{1} x \bar{l}+\frac{\tilde{d} \bar{D}_{t}}{d t}+\bar{\omega} x \bar{D}_{t}$,

where $\bar{l}$ is the distance between the mass center of the aircraft and the center of the tracking device;

$\bar{W}$ - flight velocity vector of the aircraft;

$\bar{\omega}_{1}$ - vector of the angular velocity of the aircraft;

$\frac{\tilde{d} \bar{D}_{t}}{d t}$ - relative speed of the target to the tracking device;

$\bar{\omega}$ - vector of the angular velocity of the tracking device;

The projection of the target velocity $\left(\bar{V}_{t}\right)_{1}$ in a bound coordinate system $\mathrm{Ox}_{1} \mathrm{y}_{1} \mathrm{z}_{1}$ is determined by the formula: 


$$
\begin{aligned}
V_{t x 1}= & W_{x 1}-W_{r r}(\cos \vartheta \cos \mu \cos \varphi+\sin \vartheta \sin \mu \cos \varphi)- \\
& -W_{r i}(-\cos \vartheta \sin \mu+\sin \vartheta \cos \mu)- \\
& -W_{r j}(\cos \vartheta \cos \mu \sin \varphi+\sin \vartheta \sin \mu \sin \varphi) ; \\
V_{t y 1}= & W_{y 1}-W_{r r}(-\sin \vartheta \cos \gamma \cos \mu \cos \varphi+\cos \vartheta \cos \gamma \sin \mu \cos \varphi-\sin \gamma \sin \varphi)- \\
& -W_{r i}(\sin \vartheta \cos \gamma \sin \mu+\cos \vartheta \cos \gamma \cos \mu)- \\
& -W_{r j}(-\sin \vartheta \cos \gamma \cos \mu \sin \varphi+\cos \vartheta \cos \gamma \sin \mu \sin \varphi+\cos \gamma \cos \varphi) ; \\
V_{t z 1}= & W_{z 1}-W_{r r}(\sin \vartheta \sin \gamma \cos \mu \cos \varphi-\cos \vartheta \sin \gamma \sin \mu \cos \varphi-\cos \gamma \sin \varphi)- \\
& -W_{r i}(-\sin \vartheta \sin \gamma \sin \mu+\cos \vartheta \cos \gamma \cos \mu)- \\
& -W_{r j}(\sin \vartheta \sin \gamma \cos \mu \sin \varphi-\cos \vartheta \sin \gamma \sin \mu \sin \varphi+\cos \gamma \cos \varphi),
\end{aligned}
$$$$
\text { 5) }
$$

where relative road speed $\bar{W}_{r}$ is calculated from formulas:

6)

$$
\begin{aligned}
& W_{r r}=-\omega_{1 i} l_{j}+\omega_{1 j} l_{i}-\dot{D}_{t} ; \\
& W_{r i}=\omega_{1 r} l_{j}-\omega_{1 j} l_{r}-\omega_{j} D_{t} ; \\
& W_{r j}=-\omega_{1 r} l_{i}+\omega_{1 i} l_{r}+\omega_{i} D_{t} .
\end{aligned}
$$

Projection of the vector $\bar{D}_{m}$ in a coordinate system $\mathrm{Ox}_{1} \mathrm{y}_{1} \mathrm{Z}_{1}$ is determined by the formula:

7)

$$
\left(\bar{D}_{m}\right)_{1}=\left[\begin{array}{c}
X_{t} \cos \vartheta-H \sin \vartheta \\
-X_{t} \sin \vartheta \cos \gamma-H \cos \vartheta \cos \gamma+Z_{t} \sin \gamma \\
X_{t} \sin \vartheta \sin \gamma+H \cos \vartheta \sin \gamma+Z_{t} \cos \gamma
\end{array}\right]
$$

where $X_{t}$ and $Z_{t}$ are coordinates of the point of delivery of the load in the horizontally stabilized coordinate system Oxyz, calculated by the system of differential equations for body movement in space.

The vector $(\bar{B})_{1}$ in a system $\mathrm{Ox}_{1} \mathrm{y}_{1} \mathrm{Z}_{1}$ is defined by the formula:

8) $(\bar{B})_{1}=\left[\begin{array}{l}B_{x 1} \\ B_{y 1} \\ B_{z 1}\end{array}\right]$,

Projection of the distance vector is obtained by formulas (2), (3), (7) and (8) 
$(\bar{D})_{1}:$

$\left[\begin{array}{c}D_{d x 1} \\ D_{d y 1} \\ D_{d z 1}\end{array}\right]=\left[\begin{array}{c}X_{t} \cos \vartheta-H \sin \vartheta \\ -X_{t} \sin \vartheta \cos \gamma-H \cos \vartheta \cos \gamma+Z_{t} \sin \gamma \\ X_{t} \sin \vartheta \sin \gamma+H \cos \vartheta \sin \gamma+Z_{t} \cos \gamma\end{array}\right]-\left[\begin{array}{c}B_{x 1} \\ B_{y 1} \\ B_{z 1}\end{array}\right]-$

9)

$$
\left[\begin{array}{c}
W_{x 1}-W_{r r}(\cos \vartheta \cos \mu \cos \varphi+\sin \vartheta \sin \mu \cos \varphi)-W_{r i}(-\cos \vartheta \sin \mu+\sin \vartheta \cos \mu)- \\
-W_{r j}(\cos \vartheta \cos \mu \sin \varphi+\sin \vartheta \sin \mu \sin \varphi) \\
W_{y 1}-W_{r r}(-\sin \vartheta \cos \gamma \cos \mu \cos \varphi+\cos \vartheta \cos \gamma \sin \mu \cos \varphi-\sin \gamma \sin \varphi)- \\
-W_{r i}(\sin \vartheta \cos \gamma \sin \mu+\cos \vartheta \cos \gamma \cos \mu)- \\
-W_{r j}(-\sin \vartheta \cos \gamma \cos \mu \sin \varphi+\cos \vartheta \cos \gamma \sin \mu \sin \varphi+\cos \gamma \cos \varphi) ; \\
W_{z 1}-W_{r r}(\sin \vartheta \sin \gamma \cos \mu \cos \varphi-\cos \vartheta \sin \gamma \sin \mu \cos \varphi-\cos \gamma \sin \varphi)- \\
-W_{r i}(-\sin \vartheta \sin \gamma \sin \mu+\cos \vartheta \cos \gamma \cos \mu)- \\
-W_{r j}(\sin \vartheta \sin \gamma \cos \mu \sin \varphi-\cos \vartheta \sin \gamma \sin \mu \sin \varphi+\cos \gamma \cos \varphi)
\end{array}\right] \cdot T
$$

Angles $\mu_{1 \mathrm{~d}}^{\prime}, \varphi^{\prime}{ }_{1 \mathrm{~d}}$ of the point of delivery of the load are determined by formulas (Fig. 1):

$$
\mu_{1 d}^{\prime}=\operatorname{arctg}\left(\frac{D_{d y 1}}{D_{d x 1}}\right) ; \quad \varphi_{1 d}^{\prime}=\operatorname{arctg}\left(\frac{D_{d z 1} \sin \mu_{1 d}^{\prime}}{D_{d y 1}}\right) .
$$

The structural scheme of the on-board aviation load delivery system (ADS) at a given point is based on the mathematical model (Fig. 4).

The structure of the ADS consists of:

- tracking system;

- a mathematical model for determining the target speed $\mathrm{V}_{\mathrm{t}}$;

- a ballistic model;

- a mathematical model for determining the distance to the point of encountering the load with the target $\mathrm{D}_{\mathrm{t}}$;

- a block for determining the angular coordinates $\mu_{1 \mathrm{~d}}^{\prime}, \varphi^{\prime}{ }_{1 \mathrm{~d}}$ of the point of delivery of the load

- at the point of delivery of the load;

- ballistic block;

- block with input parameters;

- A head-up display (HUD);

- Specific Ground Range (SGR).

The algorithm of a flight aviation system operation, automatically defining the moment of separation, has been developed based on mathematical models (Fig. 5). 


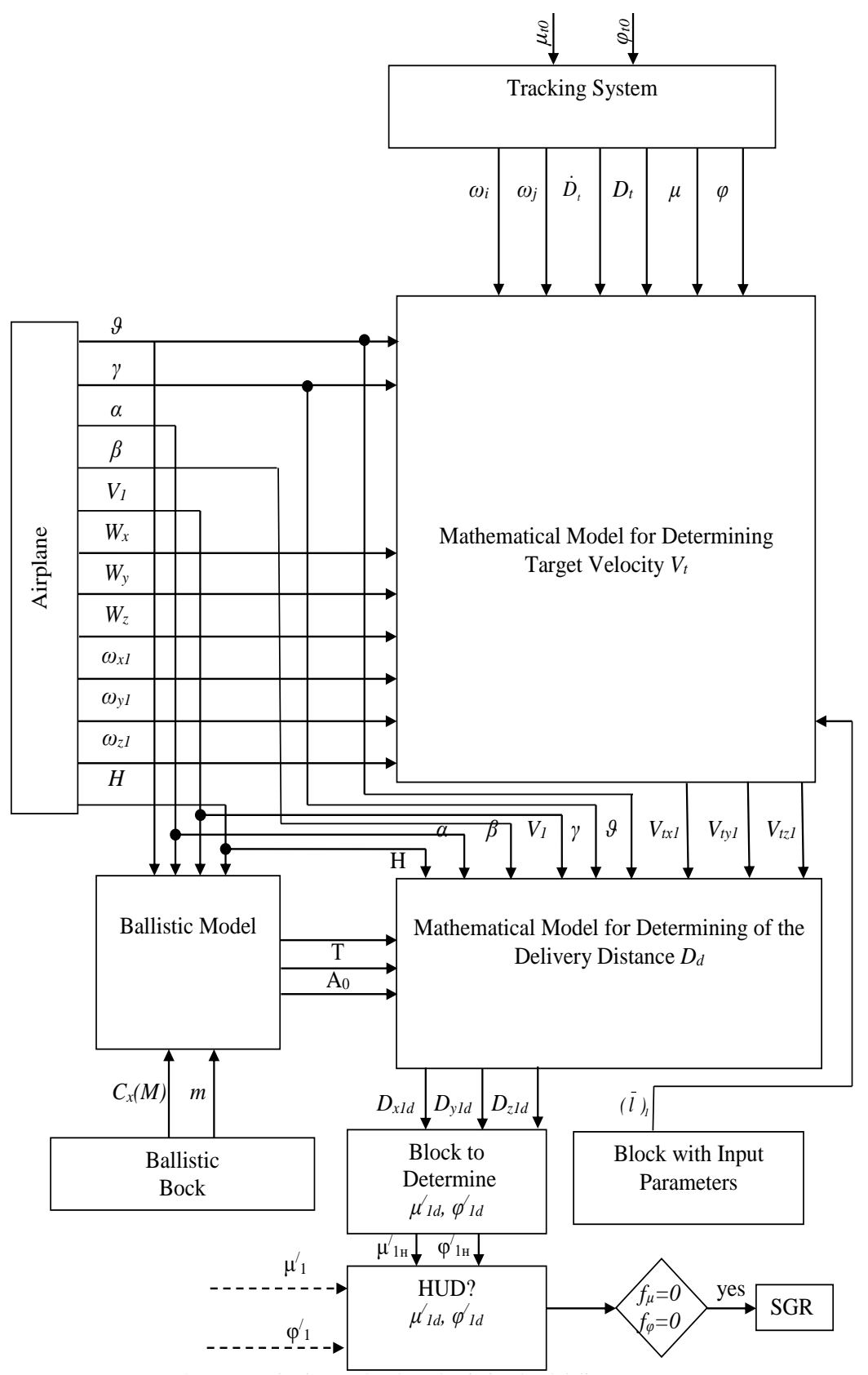

Fig. 4. Structural scheme of on-board aviation load delivery system 


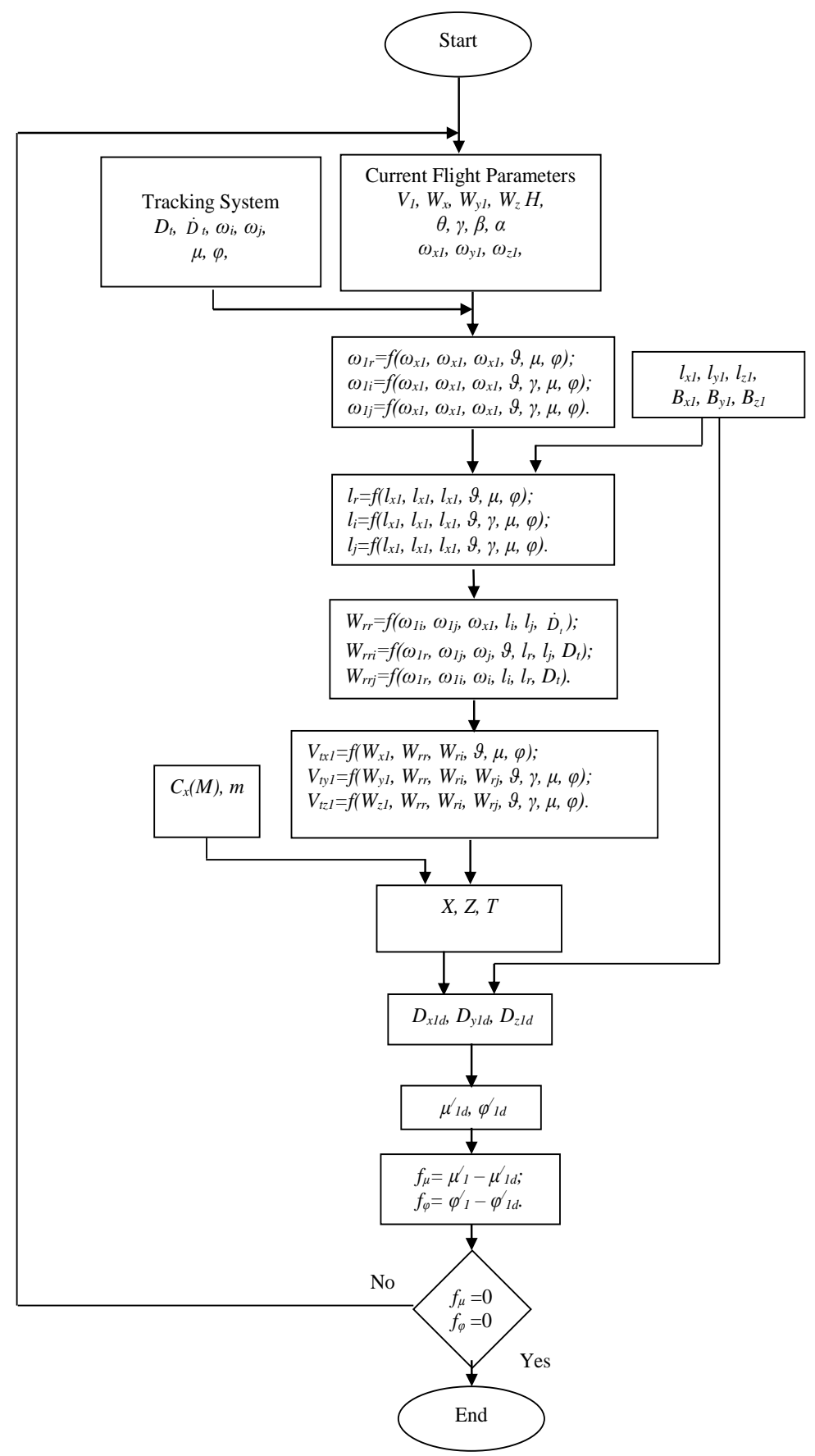

Fig. 5. Workflow algorithm of on-board aviation load delivery system 
Using the developed mathematical model and operating algorithm of an aviation board system with a tracking system, the accuracy of load delivery is determined at a point that is mobile.The accuracy in horizontal flight of the load aircraft with the drag coefficient $C_{x}=0.466$ [3].

Speed of the target is $60 \mathrm{~km} / \mathrm{h}$ with course angle $\psi_{t}=30^{\circ}$.

The test shall be carried out for the following load separation conditions:

- horizontal flight;

- $\quad$ speeds $-V=180 ; 200 ; 220 ; 240 ; 260 \mathrm{~m} / \mathrm{s}$;

- $\quad$ altitudes $-H=600 ; 900 ; 1200 ; 1500 ; 1800 \mathrm{~m}$.

Load separation error is the sum of a random and systematic error. As a consequence of this it is necessary to take some of its meanings. Considering that in most cases its sign is not of interest, the formula for the estimation of the accuracy of the load separation is used $[1,2,4]$ :

11)

$$
\sqrt{\alpha_{2 \Delta x}}=\sqrt{M^{2}[\Delta x]+D[\Delta x]},
$$

where $\mathrm{M}[\Delta \mathrm{x}]$ is the mathematical expectation of the error;

$-\mathrm{D}[\Delta \mathrm{x}]$ is error dispersion.

The results of the conducted study are shown in Tables 1 and Fig. 6 .

Table 1. The accuracy $\sqrt{\alpha_{2 \Delta x}}$ of delivery of load at a moving point

\begin{tabular}{|c|r|c|c|c|c|}
\hline \multicolumn{7}{|c|}{$\lambda=\boldsymbol{0}^{\mathbf{0}}-$ horizontal flight } \\
\hline$\sqrt{\alpha_{2 \Delta x}}[\mathbf{m}]$ & $\boldsymbol{V}=\mathbf{1 8 0}[\mathbf{m} / \mathbf{s}]$ & $\mathbf{2 0 0}$ & $\mathbf{2 2 0}$ & $\mathbf{2 4 0}$ & $\mathbf{2 6 0}$ \\
\hline $\boldsymbol{H = 6 0 0}[\mathbf{m}]$ & 20.79 & 23.40 & 25.84 & 28.30 & 31.22 \\
\hline $\mathbf{9 0 0}$ & 24.91 & 28.18 & 31.59 & 35.00 & 37.55 \\
\hline $\mathbf{1 2 0 0}$ & 29.40 & 33.10 & 36.71 & 40.77 & 44.32 \\
\hline $\mathbf{1 5 0 0}$ & 33.25 & 37.40 & 41.77 & 46.48 & 51.16 \\
\hline $\mathbf{1 8 0 0}$ & 37.35 & 42.54 & 46.45 & 51.69 & 56.87 \\
\hline
\end{tabular}

As shown in Table 1 and Fig. 6:

- the accuracy $\sqrt{\alpha_{2 \Delta x}}$ of delivery of load at a moving point when it is separated from a horizontal flight is in the range from $20.79 \mathrm{~m}$ to $56.87 \mathrm{~m}$. 

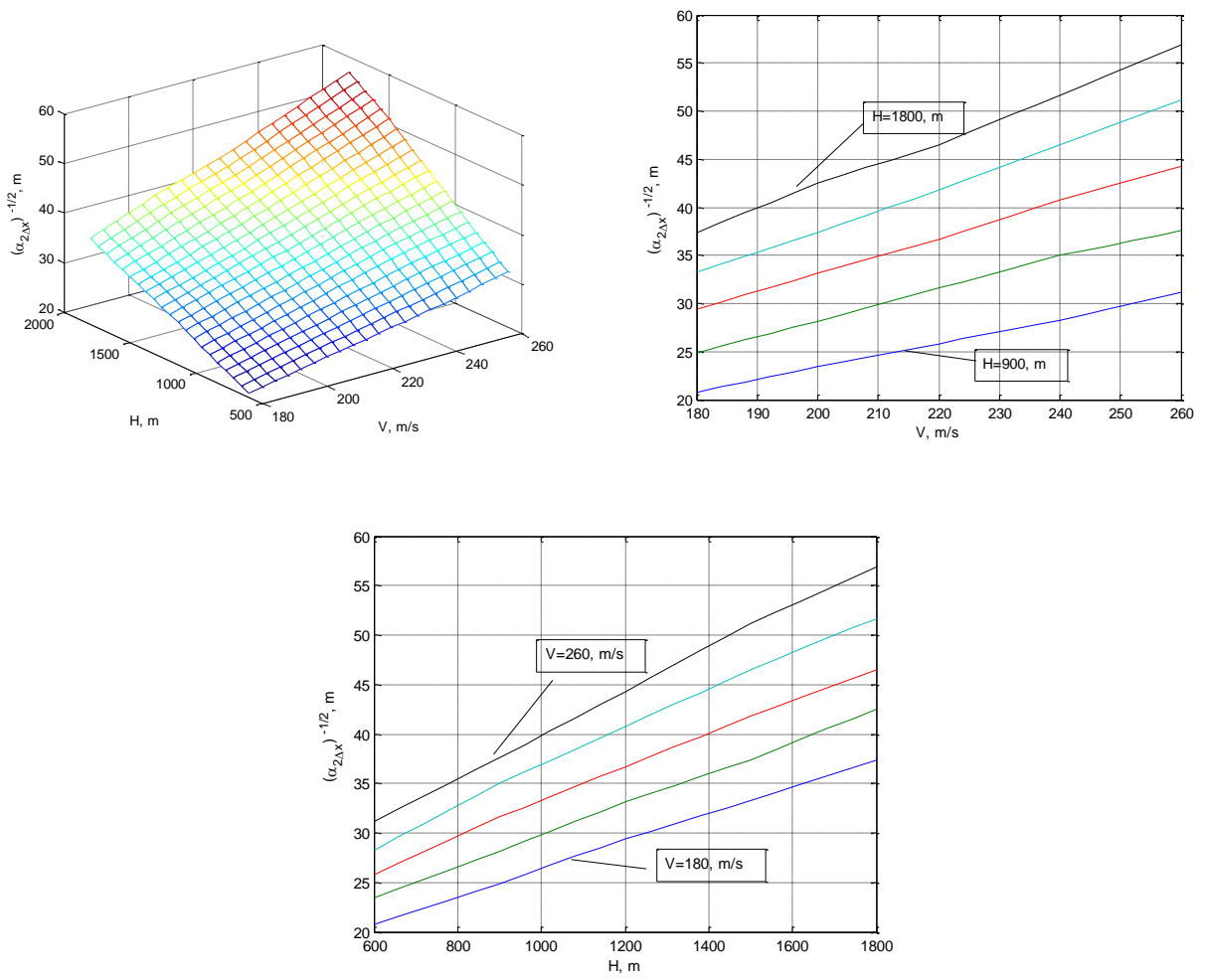

Fig. 6. Dependence of $\sqrt{\alpha_{2 \Delta x}}$ by $V$ and H for delivering a load to a moving point

The accuracy of load delivery $\left(C_{x}=0.466\right)$ at a point that is stationary when the load is loaded from a horizontal flight from an aircraft (Table 2 and Fig. 7).

Table 1. The accuracy $\sqrt{\alpha_{2 \Delta x}}$ of delivery of load at a fixed point

\begin{tabular}{|c|r|r|r|r|r|}
\hline \multicolumn{7}{|c|}{$\lambda=\boldsymbol{0}^{\mathbf{0}}-$ horizontal flight } \\
\hline$\sqrt{\alpha_{2 \Delta x}}[\mathbf{m}]$ & $\boldsymbol{V = 1 8 0}[\mathbf{m} / \mathbf{s}]$ & $\mathbf{2 0 0}$ & $\mathbf{2 2 0}$ & $\mathbf{2 4 0}$ & $\mathbf{2 6 0}$ \\
\hline $\boldsymbol{H = 6 0 0}[\mathbf{m}]$ & 18.98 & 21.13 & 22.78 & 24.74 & 26.92 \\
\hline $\mathbf{9 0 0}$ & 21.81 & 24.00 & 26.75 & 29.49 & 32.18 \\
\hline $\mathbf{1 2 0 0}$ & 24.65 & 27.62 & 30.37 & 33.41 & 36.21 \\
\hline $\mathbf{1 5 0 0}$ & 28.00 & 30.49 & 34.28 & 37.69 & 40.99 \\
\hline $\mathbf{1 8 0 0}$ & 30.48 & 34.37 & 37.50 & 40.92 & 45.93 \\
\hline
\end{tabular}



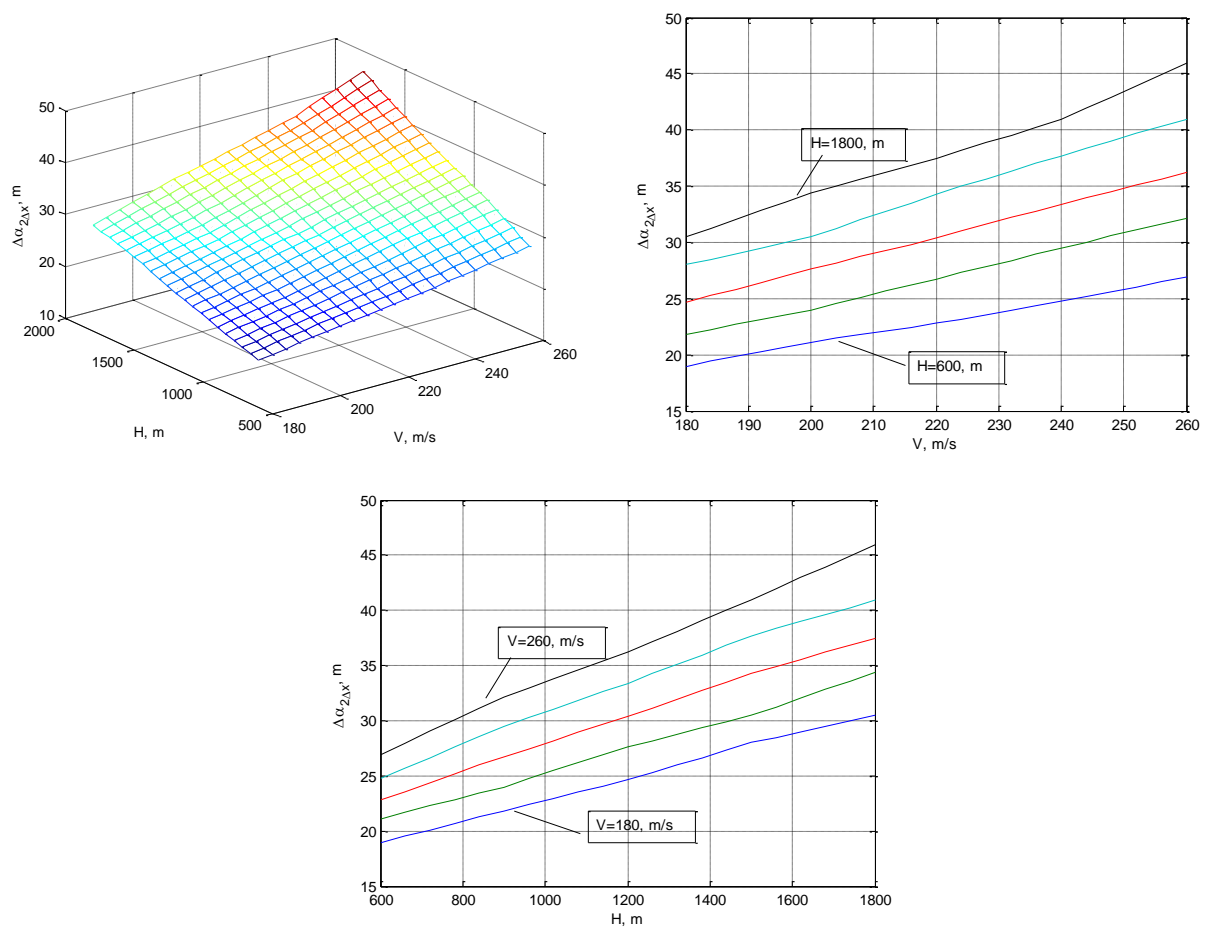

Fig. 7. Dependency of $\sqrt{\alpha_{2 \Delta x}}$ by $V$ and $H$ for delivering a load to a stationary point

As shown in Table 2 and Fig. 7:

- the accuracy of delivering load $\sqrt{\alpha_{24 x}}$ from a horizontal flight to a fixed point is in the range of $18.98 \mathrm{~m}$ to $45.93 \mathrm{~m}$.

\section{Conclusion}

The use of a tracking system in aviation flight systems provides commensurate accuracy for delivering load to a mobile and stationary point. This accuracy is approaching that of using freight that can be self-directed.

The developed mathematical apparatus and operating algorithm of aviation aboard system provides the use of fire extinguishing equipment on mobile sea platforms and hard-to-reach terrestrial areas. 


\section{References}

1. Stojkov, S. O, Stojkov O. S., Izchisljavane na verojatnostnite harakteristiki na tochnostta na bombopuskane s prinuditelno otdeljane na bombata, VI International scientific and technical conference, Engineering, Technologies, Education, Security, Proceedings, Vol. I, Military Science and Security, 27-29, Veliko Tarnovo, 2018, ISSN 2535-0315, 30-32 pp. 2018. (in Bulgarian)

2. Stojkov, O. S., Opredeljane na verojatnostnite harakteristiki na greshkata na bombopuskane, NVU "V. Levski", fakultet "Aviacionen", nauchna konferencija, Vol. 1, D. Mitropolija, 2011, pp. 46-53, ISBN 978-954-713-101-9. (in Bulgarian)

3. Stojkov, S. O., Izchisljavane na koeficienta na chelno s"protivlenie na prakticheska aviacionna bomba, Godishna mezhdunarodna nauchna konferencija na fakultet „Aviacionen“ 2018, pp. 287-289, ISBN 978-954-713-114-9. (in Bulgarian)

4. Stojkov, O. S., Formula za opredeljane na verojatnoto otklonenie na popadenieto na bombata za unificiranija metod, 2010, NVU "V. Levski", fakultet "Aviacionen", nauchna konferencija, D. MitropoliJa, pp. 85-86, 978-954-713-094-4. (in Bulgarian)

5. Stojkov, O., Atanasov M., Aviacionni pricelni sistemi - Part 1, VGC, D. Mitropolija, 2009 г., ISBN 978-954-713-093-7. (in Bulgarian)

\section{МАТЕМАТИЧЕСКИ МОДЕЛ И АЛГОРИТЬМ НА РАБОТА НА СИСТЕМА ЗА ОТДЕЛЯНЕ НА ТЯЛО ОТ ЛЕТАТЕЛЕН АПАРАТ}

\section{M. Атанасов}

\section{Резюме}

Развитието на технологиите позволява точното доставяне на товари от летателен апарат на точно определено място с помощта на бордни авиационни системи. За тази цел е предложен математически модел и алгоритъм на работа на бордна авиационна система, която в зависимост от полетните параметри и координатите на точката за доставяне на товара се определя автоматично момента на отделяне. 